\title{
A Retrospective Cross Sectional Study of Blood Culture Results in a Tertiary Hospital, Ekiti, Nigeria
}

\author{
Iheanacho Nwadioha ${ }^{1}$, Michael Simidele Odimayo ${ }^{2}$, John Omotayo ${ }^{3}$, Adebola Olu-Taiwo ${ }^{4}$, \\ Enoch Olabiyi² \\ ${ }^{1}$ Medical Microbiology and Parasitology Department, College of Health Sciences, Benue State University, \\ Makurdi, Nigeria \\ ${ }^{2}$ Medical Microbiology and Parasitology Department, College of Medicine, Ekiti State University, Ado Ekiti, Nigeria \\ ${ }^{3}$ Histopathology Department, College of Medicine, Ekiti State University, Ado Ekiti, Nigeria \\ ${ }^{4}$ Haematology and Blood Transfusion Department, Ekiti State University Teaching Hospital, Ado Ekiti, Nigeria \\ Email: 'samnwa2000@yahoo.com, simideledimayo@yahoo.com, tunjiomotayo@yahoo.co.uk, \\ docdebola@yahoo.co.uk
}

Received 16 October 2015; accepted 1 December 2015; published 4 December 2015

Copyright (C) 2015 by authors and Scientific Research Publishing Inc.

This work is licensed under the Creative Commons Attribution International License (CC BY).

http://creativecommons.org/licenses/by/4.0/

(c) (i) Open Access

\section{Abstract}

The current study was conducted to determine the epidemiology and antibiotic sensitivity pattern of bacteria isolated from blood of septicemic patients for improved antibiotic therapy. A threeyear descriptive study was done at Microbiology Laboratory, Ekiti State University Teaching Hospital, Ado Ekiti, from April 2012 to April 2015. Information compiled from patients' records includes age, sex, isolated organisms and antibiotic susceptibility patterns. Three hundred and thirteen blood cultures were collected from neonatology and pediatrics wards, Out Patients' Department (OPD) and from other adult patients. Forty one culture plates yielded mono microbial growth (no polymicrobial growth), giving an incidence of $13.1 \%$ positive blood culture $(\mathrm{N}=41 / 313)$. There were $58.4 \%$ Gram negative bacilli and $41.6 \%$ Gram positive cocci in the microbial growth. Bacteria isolated were Staphylococcus aureus $34 \%(14 / 41)$, Klebsiella species $22 \%(9 / 41)$, Enterococci 17\% (7/41), Proteus species 12\% (5/41), Escherichia coli 7\% (3/41) and Streptococcal pneumoniae $7 \%(3 / 41)$. There was a (35\%) higher occurrence of septicemia in neonates than in any other age groups in the hospital. Bacterial sensitivity to 13 antibiotic agents was determined by antibiotics disc diffusion using modified Kirby Bauer's method. Gram-positive organisms showed a higher antibiotic sensitivity ranging from 14\% - 100\% than the Gram-negative bacteria $(11 \%$ $\mathbf{8 0} \%$ ). Staphylococcus aureus and Klebsiella species are the most prevalent organisms. The third generation Cephalosporins (Ceftriaxone) and Floroquinolone (Levofloxacin, Ofloxacin) have proved reliable for management of these blood infections.

${ }^{*}$ Corresponding author.

How to cite this paper: Nwadioha, I., Odimayo, M.S., Omotayo, J., Olu-Taiwo, A. and Olabiyi, E. (2015) A Retrospective Cross Sectional Study of Blood Culture Results in a Tertiary Hospital, Ekiti, Nigeria. Open Journal of Medical Microbiology, 5, 202-208. http://dx.doi.org/10.4236/ojmm.2015.54025 


\section{Keywords}

\section{Blood Cultures, Septicemia, Antibiogram, Nigeria}

\section{Introduction}

Septicemia is a common condition that is highly lethal to both pediatric and adult hospitalized patients [1]. The prognosis of neonatal septicemia in Nigeria has remained poor, with survival reports of 59\% to 67\% [1]-[3]. Blood culture remains a gold standard for the determination of microbial agents of septicemia.

Types and predominance of bacterial isolates and antibiotic susceptibility pattern are influenced by geographical location, previous antimicrobial agents used, age, pre- and co-morbid conditions and immune status. During the past decade, a change from predominance of Gram-negative to Gram-positive bacteria has occurred [3] [4]. However, virtually any microorganism can cause infection in severely immune-suppressed patients.

Low pathogen culture yield often seems to characterize adult bacteremias, hence the need for adequate blood volume for blood culture in adults [5]. Two to three paired sets of blood cultures (an aerobic and an anaerobic bottle or two aerobic bottles) are recommended for any septic episodes.

Studies have shown the following bacterial isolates from blood culture results: Escherichia coli, Streptococcus agalactiae, Klebsiella species, Pseudomonas aeruginosa, Neisseria meningitidis, Streptococcus pneumoniae, Haemophilus influenzae, Staphylococcus aureus, Streptococcus pyogenes, Coagulase negative staphylococci and Enterococcus faecium [2] [3] [6] [7].

Increase in cases of malignancies and use of chemotherapy has led to significant clinical re-emergence of anaerobic bacteremia [8]. Thus, use of aerobic and anaerobic paired set of bottles most often results in significant pathogen culture yield compared to two aerobic culture bottles [8].

Large scale antibiotic abuse has led to emergence of wide spread resistance [6]. Antibiotic resistance has much negative socio-economic impact in developing societies such as Nigeria [1]-[3]. Blood culture is out of reach to some hospitals in resource poor regions of the world. Periodic bacteriologic surveillance through blood cultures with the antimicrobial susceptibility testing therefore is a necessity [2] [7].

We hereby describe the pattern of bacterial isolates and the antibiotic sensitivity in clinical diagnosis of septicemia seen in Ekiti, western Nigeria. The study will necessitate antimicrobial stewardship programs in this locale.

\section{Method}

This descriptive study reviewed the three year records of 313 blood culture samples processed in Medical Microbiology Laboratory of Ekiti State University Teaching Hospital (EKSUTH) from April, 2012 to April, 2015.

Epidemiologic data were retrieved from the register/record book of blood culture results in the Medical Microbiology laboratory. As many with suspected septicemic condition that were referred from the clinics and wards of the hospital to the laboratory for blood culture were enrolled for the study irrespective of age, sex and status.

\subsection{Sample Collection}

A paired set of blood samples was collected in aseptic condition prior to any antibiotic medication, each from a different site of the body. One milliliter sample of blood from neonates was inoculated into $10 \mathrm{mls}$ of blood culture broth and $5 \mathrm{ml}$ sample of blood from children (>28/7 - 14 yrs) was collected and introduced into $50 \mathrm{ml}$ of blood culture broth, while $10 \mathrm{ml}$ sample was collected from age group above 14 years (>14 yr-adult) and inoculated into $50 \mathrm{ml}$ broth respectively (brain heart infusion broth [1:10 or 1:5 dilution]). This was done by clinicians, trained nurses or trained laboratory staff by applying sterile procedures.

\subsection{Bacteriological Processing}

Brain Heart Infusion broth (Oxoid UK) inoculated with blood was transported to the laboratory and incubated at $37^{\circ} \mathrm{C}$ for 7 days. Growth in both bottles assigned for each patient was considered positive. All the bottles were 
examined for turbidity, hemolysis, and pellicle formation. Subcultures were performed at 24 hours, 72 hours and on the 7th day. Final subcultures were done on the 7th day before reporting culture as negative. The subcultures were on Blood agar and Mac Conkey agar plates and were incubated overnight at $37^{\circ} \mathrm{C}$ in aerobic atmosphere while chocolate agar plates were incubated in $5 \%$ carbon dioxide $\left(\mathrm{CO}_{2}\right)$. Growth obtained was examined for colony and Gram-staining characteristics. Conventional biochemical tests were performed on inocula from purity plates using standard microbiological methods [9].

\subsection{Antibiotic Susceptibility Testing}

Modified Kirby-Bauer disk diffusion technique was used according to Clinical and Laboratory Standards Institute (CLSI) 2006 guidelines, with the tables for interpretative inhibition zone diameters of CLSI criteria [10]. The antibiotic disks (Oxoid) used were as follows; trimethoprim-sulphamethoxazole $(25 \mu \mathrm{g})$, tetracycline (30 $\mu \mathrm{g})$, ampicillin $(10 \mu \mathrm{g})$, amoxicillin $(30 \mu \mathrm{g})$, penicillin (10 IU), ceftriaxone $(30 \mu \mathrm{g})$, ceftazidime $(30 \mu \mathrm{g})$, chloramphenicol $(30 \mu \mathrm{g})$, ciprofloxacin $(5 \mu \mathrm{g})$, ofloxacin $(5 \mu \mathrm{g})$, levofloxacin $(5 \mu \mathrm{g})$, erythromycin $(15 \mu \mathrm{g})$ and gentamycin $(10 \mu \mathrm{g})$. Control bacterial strains that were used included Staphylococcus aureus ATCC 25923, Escherichia coli ATCC 25922 and P. aeruginosa ATTC 27853.

\subsection{Analysis of Data}

Data were analyzed using SPSS version 16.00 software. Chi-square $\left(\mathrm{X}^{2}\right)$ was used to compare association between proportions. And P-value of $<0.05$ was considered significant at $95 \%$ confidence level.

\subsection{Ethical Consideration}

Ethical clearance was obtained from Hospital Ethics Committee of Ekiti State University Teaching Hospital.

\section{Results}

Total number of blood cultures processed were 313 from April 2012 to April 2015. Fifty five per cent was for females while $45 \%$ was for males $(n=172 / 313, n=141 / 313)$. The median age was 34.0 years. Ninety five percent (297/313) were inpatients while 5\% (16/313) were outpatients. Forty-three per cent (134/313) of patients were adults and adolescents ( $>14$ yr-Adults), 13\% (41/313) were of age between 6 years and 14 years ( $>6$ yrs - 14 yrs), $12 \%$ (39/313) were of age between 6 months and 6 years (>6/12 - 6 yrs), 6.7\% (21/313) were of age greater than 28 days to 6 months (>28/7 - 6/12) and 16\% (51/313) were neonates ( $\leq 28 / 7)$ (Figure 1$)$. Total rate of bacteria isolated (total pathogen culture yield) was $13.1 \%$ [ $=41 / 313$ ] (Table 1). Monomicrobial growth only was isolated. The pathogens were as follows; Staphylococcus aureus 34\%(14/41), Klebsiella spp. 22\% (9/41), Enterococci 17\% (7/41), Proteus spp. 12\% (5/41), Escherichia coli 7\% (3/41), Streptococcal spp. 7\% (3/41).

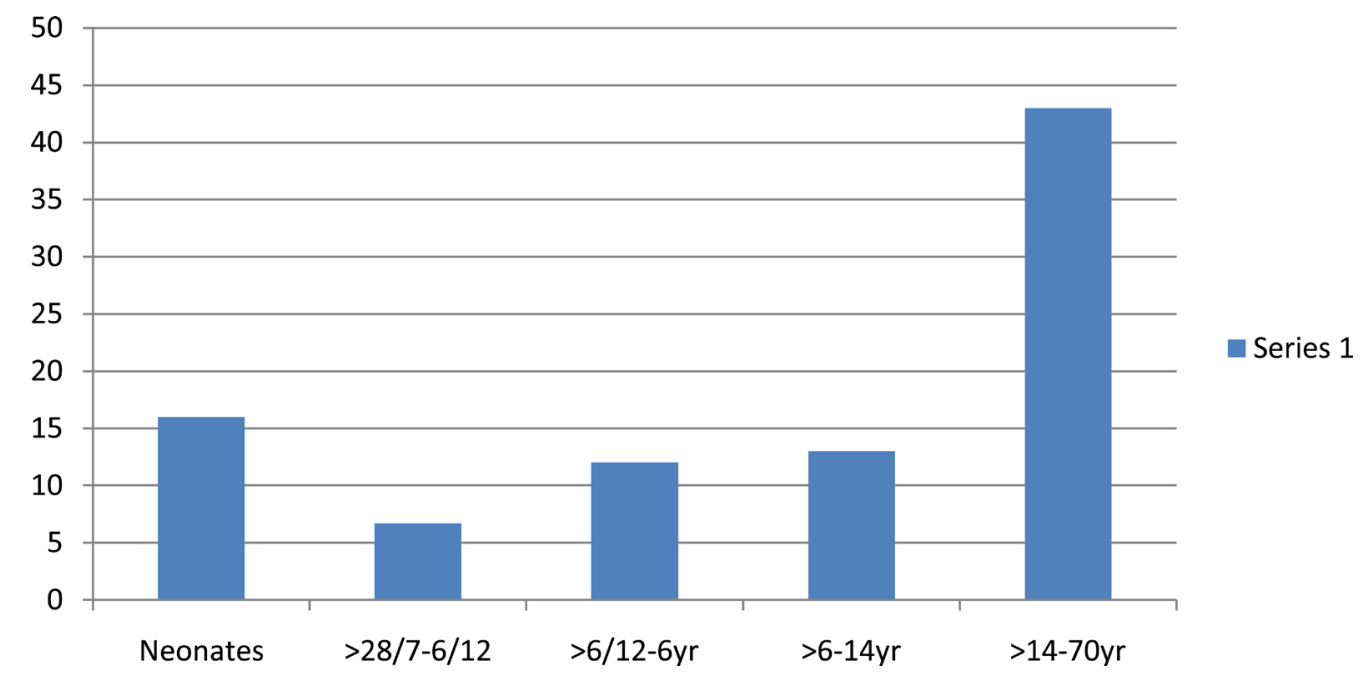

Figure 1. Age distribution of patients with suspected septicemia at EKSUTH from April 2012 to April 2015. 
The Gram positive bacteria constituted 58.5\% (24/41) while Gram negative bacteria, 41.5\% (17/41) of the culture isolates (Figure 2). Neonates had the highest pathogen culture yield (highest rate of bacteria isolates) with 18/51(35\%) (Table 1 \& Figure 3). The following were the antibiotics activities across the spectrum of bacterial

Table 1. Age groups of septicemic patients and their bacterial isolates at Ekiti state university teaching hospital from April 2012 to April 2015.

\begin{tabular}{|c|c|c|c|c|c|c|}
\hline \multirow[b]{2}{*}{ BACTERIA } & \multicolumn{3}{|c|}{ AGE } & \multicolumn{3}{|l|}{ GROUPS } \\
\hline & $\begin{array}{c}\text { A } \\
\text { Neonates (\%) }\end{array}$ & $\begin{array}{c}\text { B } \\
>28 / 7-6 / 12(\%)\end{array}$ & $\begin{array}{c}\text { C } \\
>6 / 12-6 \text { yrs }(\%)\end{array}$ & $\begin{array}{c}\mathrm{D} \\
>6 \text { yrs }-14 \text { yrs (\%) }\end{array}$ & $\underset{\mathrm{E}}{\mathrm{E}}$ & $\begin{array}{c}\text { TOTAL } \\
(\%)\end{array}$ \\
\hline *S. aureus & 6 & 1 & 1 & 2 & 4 & 14 \\
\hline Kleb. spp. & 6 & - & 1 & 1 & 1 & 9 \\
\hline Enterococci & 3 & - & 1 & - & 3 & 7 \\
\hline Proteus spp. & 2 & 1 & - & - & 2 & 5 \\
\hline E. coli & 1 & - & - & 1 & 1 & 3 \\
\hline Strep. pneum & - & 1 & - & - & 2 & 3 \\
\hline Total isolates & 18 & 3 & 3 & 4 & 13 & 41 \\
\hline Sterile (negative) cultures & 33 & 18 & 36 & 37 & 121 & 272 \\
\hline Total Cultures & 51 & 21 & 39 & 41 & 134 & 313 \\
\hline
\end{tabular}

${ }^{*}$ S. aureus = Staphylococcus aureus; Kleb. = Klebsiella; E. coli = Escherichia coli; Strep. pneum = Streptococcus pneumoniae; spp. = species; $-=$ Nil.

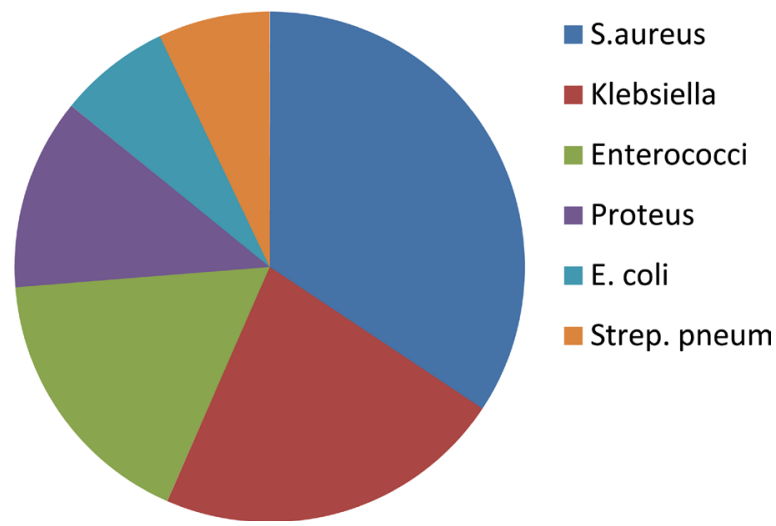

Figure 2. Frequency of the bacterial isolates from septicemic patients at Ekiti state university teaching hospital from April 2012-April 2015.

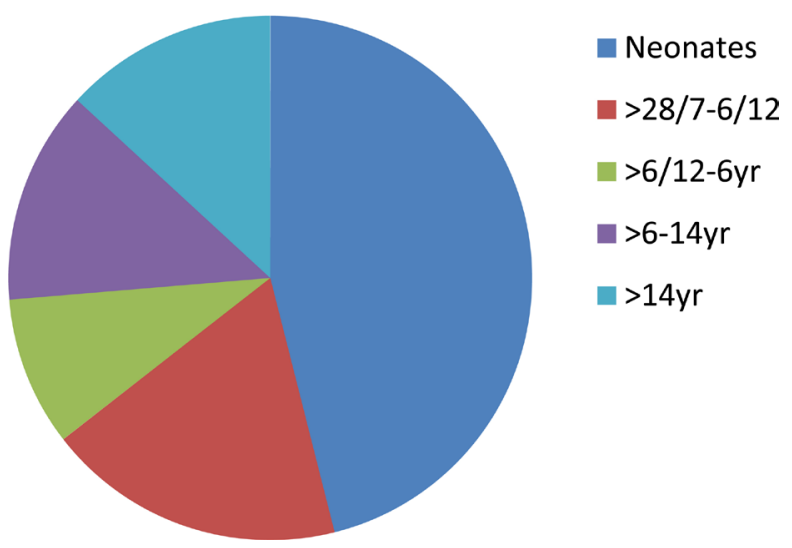

Figure 3. Frequency of positive culture results according to ages of the sample populations in Ekiti state university teaching hosp from April 2012 to April 2015. 
isolates: Cefriaxone (88\%), Levofloxacin (82\%), Ofloxacin (70\%), Ciprofloxacin (67\%), Tetracyclin (11\%), Penicillin (20\%) (Table 2). Gram-positive bacterial antibiotic susceptibility ranged from $14 \%$ to $100 \%$ while, Gram-negative bacteria ranged from $11 \%$ to $80 \%$. Seventy to eighty-five per cent of Staphylococcus aureus were sensitive to ceftriaxone and floroquinolones (levofloxacin, ofloxacin), though ciprofloxacin was losing grip (with only 67\% compared to $82 \%$ for levofloxacin). Klebsiella spp. was 70\% sensitive to Ceftazidime and Ofloxacin (Table 2).

\section{Discussion}

The study has demonstrated the bacterial antibiotic sensitivity pattern in septicemic patients in western Nigeria. The rate (13.1\%) of positive culture results was lower than some earlier studies in Nigeria, such as $18.2 \%$ [1], 24.5\% [2], 44.9\% [3], 30.8\% [11], 33.1\% [12], 34.4\% [13]. It was as much lower than some other studies outside the country namely, $22.9 \%$ [14], 24.5\% [15], 42\% [16]. However, our report was higher than some other studies in and outside Nigeria; 4.1\% [17], 10.7\% [18].

The rate of positive cultures (pathogen yield per cultures) of $35 \%$ in neonates was more compared to the adults and other pediatrics age groups (Figure 3). The high incidence of positive culture in neonates in the study may either suggest that neonatologists were more exact in their clinical impressions or may be attributed to higher rate septicemia due to immaturity of immune system of the new born, high rate home delivery, low socio-economic status of the parents, poor knowledge of good hygiene practices or bottle feeding [7]. However, this seeming contradiction seen in older age groups may be due to ingestion of antibiotics prior to blood sample collection, a situation that lowers the true positive rate in the adult population in an environment of inappropriate antibiotics use like ours.

Sterile blood culture contributed $87 \%$ in the study. According to studies [1] [19], most Nigerian patients indulge in self antibiotic medication before presenting to hospital, which may account for the high incidence of blood culture negativity. This quagmire can be overcome by newer non growth dependent diagnostics such as Polymerase chain reaction and Latex agglutinations; which unfortunately, are not readily available in most medical laboratory practices in Nigeria.

In similarity to some other studies [1] [2] [20]-[22]; S. aureus and Klebsiella species were the predominant causative agents of septicemia in the study. Gram-positive bacteria showed $14 \%$ to $100 \%$ antibiotic susceptibility to the available antibiotics, while the Gram-negative bacteria had $11 \%$ to $80 \%$. This suggests a higher rate of

Table 2. Antibiotic sensitivity of the bacterial isolates from the sample population in Ekiti state university teaching hospital, April 2012 to April 2015.

\begin{tabular}{|c|c|c|c|c|c|c|}
\hline \multirow{2}{*}{ DRUGS } & \multicolumn{6}{|l|}{ BACTERIAL } \\
\hline & ${ }^{* *}$ S. aureus $14(\%)$ & Klebsiella spp. 9(\%) & Enterococci 7(\%) & Proteus spp. 5(\%) & E. coli $3(\%)$ & Strep. Pneum 3(\%) \\
\hline *PEN & 2(14) & $0(0)$ & $2(28)$ & $1(20)$ & - & $1(33)$ \\
\hline AMP & 2(14) & - & - & $3(60)$ & 1(33) & $1(33)$ \\
\hline AMX & - & - & - & - & 1(33) & - \\
\hline CHLOR & $4(28)$ & $3(33)$ & 2(28) & - & - & $2(66)$ \\
\hline TCN & - & - & - & $0(0)$ & $1(33)$ & - \\
\hline GENT & $10(71)$ & $5(55)$ & $3(42)$ & $3(60)$ & $2(66)$ & $2(66)$ \\
\hline ERYTH & $7(50)$ & $1(11)$ & $3(42)$ & - & $0(0)$ & - \\
\hline SXT & 2(14) & $3(33)$ & - & $2(40)$ & - & - \\
\hline CEFTR & $11(78)$ & - & $6(85)$ & - & - & $3(100)$ \\
\hline CEFT & & $7(77)$ & - & $4(80)$ & 2(66) & - \\
\hline CIPRO & $10(71)$ & $6(66)$ & $5(71)$ & $3(60)$ & - & $2(66)$ \\
\hline OFL & $11(78)$ & $7(77)$ & - & - & $2(66)$ & - \\
\hline LEV & $11(78)$ & - & $6(85)$ & $4(80)$ & $2(66)$ & $3(100)$ \\
\hline
\end{tabular}

${ }^{*}$ PEN = Penicillin; AMP = Ampicillin; AMX = Amoxicillin; CHLOR = Chloramphenicol; TCN = Tetracycline; GENT = Gentamicin; ERYTH = Erythromycin; SXT = Trimethoprim-Sulphamethoxazole; CEFTR = Ceftriaxone; CEFT = Ceftazidime; CIPRO = Ciprofloxacin; OFL = Ofloxacin; LEV = Levofloxacin; ${ }^{* *}$ S. aureus = Staphylococcus aureus; Strep.pneum. = Streptococcus pneumoniae; E. coli = Escherichia coli; spp. = species; NOT DONE. 
resistance in Gram negative than in Gram positive bacteria. The common empirical drugs (Trimethoprimsulphamethoxazole, Ampicillin, Penicillin, Chloramphenicol and Erythromycin) showed low activity (14\% $50 \%)$ to the predominant pathogen, S. aureus. These are drugs that are easily bought over the counter and are sold by drug hawkers. Similar to other studies done in Nigeria (Benue and Calabar) [1] [3], Gentamycin remained averagely $60 \%$ effective. Being an injectible, gentamicin may not easily be abused.

The third generation cephalosporin (Ceftriaxone, Ceftazidime) tested had the most effective anti-bacterial activity. Unfortunately this group of antibiotics is readily hydrolysed by Extended Spectrum Beta-lactamase enzyme (ESBL) in Enterobacteriacea encoded in Temoneira (TEM) or sulfhydryl variable genes [1].

The floroquinolones (Levofloxacin, Ofloxacin) were almost as effective as the third generation cephalosporins. However, ciprofloxacin is losing grip in this study (about $10 \%$ lower effect than the levofloxacin). Therefore rational use of floroquinolones as a back bone in antibiotics armamentarium must be encouraged [23]-[25].

The driving force in bacterial antibiotic resistance includes poor infection control practices and irrational antibiotics usage. Therefore, antibiotic restriction, combination therapy and antibiotic cycling may help to control the emergence of resistance [24].

There was a lack of systematic selection of the study population because of the peculiar nature of retrospective study. A true representation was not reflected because of a relatively low sample size over the study time-frame. Again, non inclusion of anaerobic cultures must have contributed to low pathogen culture yield result in the study.

\section{Conclusion}

The present study shows a high incidence of bacterial resistance to most common empiric antibiotics. Therefore, there is a need to implement antibiotic stewardship programs across our health care facilities.

\section{Acknowledgements}

We deeply acknowledge the staff, trainee students, interns and national youth service corp members attached to the Medical Microbiology laboratory of the study site for their co-operation and effort in the collection of data

\section{References}

[1] Nwadioha, S.I., Nwokedi, E.O.P., Kashibu, E., Odimayo, M.S. and Okwori, E.E. (2010) A Review of Bacterial Isolates in Blood Cultures of Children with Suspected Septicemia in a Nigerian Tertiary Hospital. African Journal of Microbiology Research, 4, 222-225.

[2] Onipede, A.O., Onayade, A.A., Elusanya, J.B.E., Obiajunwa, P.O., Ogundare, E.O.O., Olaniran, O.O., et al. (2009) Invasive Bacterial Isolates from Children with Severe Infections in a Nigerian Hospital. Journal of Infection in Developing Countries, 3, 429-436. http://dx.doi.org/10.3855/jidc.413

[3] Martin, M.M., Chukwuemeka, E.N., Anne, E.A., Joseph, U.O. and Simon, E.A. (2005) Bacterial Isolates from Blood Cultures of Children with Suspected Septicemia in Calabar Nigeria. BMC Infectious Diseases, 5, 110. http://dx.doi.org/10.1186/1471-2334-5-110

[4] Kamga, H.L.F., Njunda, A.L., Nde, P.E., Assob, J.C.N., Nsagha, D.S. and Weldji, P. (2011) Prevalence of Septicaemia and Antibiotic Sensitivity Pattern of Bacterial Isolates at the University Teaching Hospital, Yaoundé, Cameroon. African Journal of Clinical and Experimental Microbiology, 300-305.

[5] Patel, R., Vetter, E.A., Harmsen, W.S. and Schleck, C.D. (2011) Optimized Pathogen Detection EA with 30-Compared to 20-Milliliter Blood Culture Draws. Journal of Clinical Microbiology, 9, 4047-4051. http://dx.doi.org/10.1128/JCM.01314-11

[6] Peter Donnally, J., Nicole, M.A., Blijlevens and Walter, J.F.M. (2015) Infection in Immunocompromised Host. In: John, E.B., Raphael, D., Martin, J.B., Eds., Mandell, Douglas and Bennett’s Principles and Practice of Infectious Diseases, Eight Edition by Saunders, 3391.

[7] Dagnew, M., Yismaw, G., Gizachew, M. and Gadisa, A. (2013) Bacterial Profile and Antimicrobial Susceptibility Pattern in Septicemia Suspected Patients Attending Gondar University Hospital, Northwest Ethiopia. BMC Research Notes, 6, 283. http://dx.doi.org/10.1186/1756-0500-6-283

[8] Lassmann, B., Gustafson, D.R., Wood, C.M. and Rosenblatt, J.E. (2007) Reemergence of Anaerobic Bacteremia. Clinical Infectious Diseases, 44, 895-900. http://dx.doi.org/10.1086/512197

[9] Forbes, B.A., Sahm, D.F. and Weisfeld, A.S. (2007) Infections of the CSF/Blood. Laboratory Manual of Bailey \& Scotts Diagnostic Microbiology, 12th Edition, Mosby Elsevier Publication, 907-916. 
[10] Clinical Laboratory Standard Institute (2006) Performance Standard for Antimicrobial Disk Susceptibility Tests; Approved Standard, 9th Edition.

[11] Fadel, H.J., Patel, R., Vetter, E.A. and Baddour, L.M. (2011) Clinical Significance of Staphylococcus Species Positive Blood Culture. Journal of Clinical Microbiology, 49, 1697-1699. http://dx.doi.org/10.1128/JCM.02058-10

[12] West, B.A. and Peterside, O. (2012) Sensitivity Pattern among Bacterial Isolates in Neonatal Septicaemia in Port Harcourt. Annals of Clinical Microbiology and Antimicrobials, 1, 7-11.

[13] Bode-Thomas, F., Ikeh, E.I. and Ejeliogu, E.U. (2004) Current Aetiology of Neonatal Sepsis in Jos University Teaching Hospital. Nigerian Journal of Medicine, 13, 130-135.

[14] Prabhu, K., Bhat, S. and Rao, S. (2010) Bacteriologic Profile and Antibiogram of Blood Culture Isolates in a Padiatric Care Unit. Journal of Laboratory Physicians, 2, 85-88. http://dx.doi.org/10.4103/0974-2727.72156

[15] Qian, Q., Eichelberger, K. and Kirby, J.E. (2014) Rapid Identification of Staphylococcus aureus Directly from Bactec Blood Culture Broth by the BinaxNOW S. aureus Test. Journal of Clinical Microbiology, 52, 319-320. http://dx.doi.org/10.1128/JCM.02291-13

[16] Rabia, S., Khan, N. and Hussain, S. (2010) Bacteriology and Antimicrobial Susceptibility of Neonatal Septicemia. Annals of Pakistan Institute of Medical Sciences, 6, 191-195.

[17] Westh, H., Lisby, G., Breysse, F. and Boddinghaus, B. (2009) Multiplex Real-Time PCR and Blood Culture for Identification of Bloodstream Pathogens in Patients with Suspected Sepsis. Clinical Microbiology and Infection, 15, 544-551. http://dx.doi.org/10.1111/j.1469-0691.2009.02736.x

[18] Piem, B.C., Sundaram, P., Raof, N. and Weinstein, M.P. (2010) The Clinical and Prognostic Importance of Positive Blood Cultures in Adults. American Journal of Medicine, 123, 819-828. http://dx.doi.org/10.1016/j.amjmed.2010.03.021

[19] Nwadioha, S.I., Onwuezube, I., Egesie, J.O., Kashibu, E. and Nwokedi, E.O.P. (2011) Bacterial Isolates from Cerebrospinal Fuid of Suspected Acute Meningitis in Nigerian Children. Emedpub-International Infectious Diseases, 1, 813.

[20] Matthew, S. and Guy, E.T. (2008) The Diagnosis and Management of Acute Bacterial Meningitis in Resource-Poor Settings. The Lancet Neurology, 7, 637-648. http://dx.doi.org/10.1016/S1474-4422(08)70139-X

[21] Youssef, D., Shams, W., Bailey, B., O’Neil, T.J. and Al-Abbadi, M.A. (2012) Effective Strategy for Decreasing Blood Culture Contamination Rates: The Experience of a Veterans Affairs Medical Centre. Journal of Hospital Infection, 81, 288-291. http://dx.doi.org/10.1016/j.jhin.2012.05.014

[22] Baur, K.A., Balada-Llasat, J.M. and Pancholi, P. (2010) An Antimicrobial Stewardship Program's Impact with Rapid Polymerase Chain Reaction Methicillin-Resistant Staphylococcus aureus/Its Culture Test in S. aureus Bacteremia. Clinical Infectious Diseases, 51, 1074-1080. http://dx.doi.org/10.1086/656623

[23] Ali, S.Q., Zehra, A., Naqvi, B.S. and Shah, S. (2010) Resistance Pattern of Ciprofloxacin against Different Pathogens. Oman Medical Journal, 25, 294-298. http://dx.doi.org/10.5001/omj.2010.85

[24] Jeng, K., Gaydos, C.A., Blyn, L.B. and Rothman, R.E. (2012) Comparative Analysis of Two Broad Range PCR Assays for Pathogen Detection in Positive Blood Culture Bottles: PCR-High Resolution Melting Analysis versus PCR-Mass Spectrometry. Journal of Clinical Microbiology, 50, 3287-3292. http://dx.doi.org/10.1128/JCM.00677-12

[25] WHO (2007) Standardized Treatment of Bacterial Meningitis in Africa in Epidemic and Non-Epidemic Situations. WHO/CDS/EPR/, 3. 